\title{
Agnostic evaluation of ipilimumab and nivolumab association: a metanalysis
}

\author{
Paolo Marchetti ${ }^{1}$, Andrea Botticelli ${ }^{1 *} \mathbb{C}$, Antonio Paolo Ascierto ${ }^{2}$, Giuseppe Curigliano ${ }^{3}$ and Diana Giannarelli ${ }^{4}$
}

\begin{abstract}
Background: Ipilimumab and Nivolumab, targeting the molecules CTLA-4, PD-1, respectively, have shown efficacy against several types of cancer. Despite these results, only a small percentage of patients maintains a long-lasting effect. Even Ipilimumab, in combination with nivolumab, has demonstrated a significant clinical benefit in multiple tumor types. However, no trial has been designed with the primary endpoint to compare the efficacy of nivolumab plus ipilimumab combined, compared to nivolumab alone. Hence, the added value of ipilimumab in the combination has not clearly been established yet. The aim of this study was to demonstrate the superiority of the combination strategy compared to the single agent therapy.

Materials and methods: We performed a meta-analysis of Phase I-II-III Clinical Trials, published from 2010 up to 2020, in which the combination of ipilimumab plus nivolumab was compared to nivolumab alone. We extracted ORR, OS and PFS HR on the basis of treatment from the subgroup analysis of each trial.

Results: A total of 7 trials were included in the present meta-analysis. Overall, 1313 patients were treated with the nivolumab plus ipilimumab combination compared to 1110 patients treated with nivolumabalone. All trials reported the Objective response rate(ORR), no heterogeneity was found among studies and the pooled Odds Ratio was highly in favor of the nivolumab plus ipilimumab combination with respect to nivolumab alone (1.683; 95\% Cl: 1.407-2.012; $P<0.0001)$. Three studies were considered for Progression free survival (PFS) analysis, and the pooled Hazard Ratio favored the combination of nivolumab plus ipilimumab with respect to nivolumab alone $(0.807 ; 95 \% \mathrm{Cl}$ : 0.719-0.907; $P<0.0001)$. The Overall survival(OS) endpoint was considered only in 2 trials, and the pooled HR favored, also in this case, the combination of nivolumab plus ipilimumab with respect to nivolumab alone $(0.87$; $95 \% \mathrm{Cl}$ : $0.763-0.997$; $P=0.045)$.
\end{abstract}

Conclusions: The combination of ipilimumab plus nivolumab seems to be superior to nivolumab alone in cancer patients, regardless of histology.

Keywords: Immunotherapy, Combination immunotherapy, Nivolumab, Ipilimumab, Agnostic approval

\section{Background}

Tumour-agnostic therapies target specific gene mutations or molecular features regardless of tumour site of origin [1]. By integrating this definition, if we consider the immune system as the selective target of immunotherapy,

\footnotetext{
${ }^{*}$ Correspondence: andrea.botticelli@uniroma1.it

1 Department of Clinical and Molecular Medicine, Sapienza, University of Rome, Policlinico Umberto I, Sant'Andrea Hospital, IDI IRCSS, Rome, Italy

Full list of author information is available at the end of the article
}

an agnostic evaluation (i.e., transversal between the different cancer types) can be made between the associations of two different immunotherapies with respect to the results obtained with only one of these.

Cancer immunotherapies that target the immunosuppressive checkpoint receptors cytotoxic T-lymphocyteassociated protein 4 (CTLA-4) or programmed death 1 (PD-1) and its ligand, programmed death 1 ligand (PD-L1), have changed the landscape of cancer treatment [2]. Ipilimumab therapy first showed a survival 
advantage in melanoma patients, when compared to a gp100 vaccine or chemotherapy [3]. Nivolumab, targeting PD-1, prolonged overall survival in multiple tumor types including melanoma, non-small cell lung cancer (NSCLC), renal cell carcinoma (RCC), head and neck carcinoma and Hodgkin's lymphoma. Despite this unprecedented efficacy, many patients fail to respond, presenting primary resistance, and more concerning, some patients who demonstrate encouraging initial responses to immunotherapy, can acquire resistance over time. It has been proposed that mechanisms promoting either primary or acquired resistance are largely conserved, and that they must affect either tumor immunogenicity, antigen presentation and generation of effector T-cells, the encounter of antigen and PD-L1 by tumor-specific T-cells, the activity and efficacy of tumor-specific immune responses or the induction of immunological memory [4]. Considering the elucidated mechanisms of resistance to anti-PD-1, it is reasonable to believe that a more accurate selection of patients and a combination of therapies might yield a greater benefit by enhancing anti-tumor activity. Indeed, Ipilimumab in combination with nivolumab has demonstrated significant clinical benefit in multiple tumor types. From an immunological point of view, it is still unclear whether the enhanced efficacy of the combination of anti-PD-1 and anti-CTLA-4 therapy is mediated by an additive effect of the cellular and molecular mechanisms of the respective therapies or, alternatively, through different and distinct mechanisms of each therapy alone [4]. However, until now, no trial has been designed with the primary end point being the comparison of the efficacy of nivolumab plus ipilimumab versus nivolumab alone and the added value of ipilimumab in the combination. The aim of this analysis is to demonstrate that the addition of ipilimumab to nivolumab results in improved efficacy among multiple solid tumors.

\section{Patients and methods}

\section{Literature search and inclusion criteria}

We identified all randomized trials evaluating the combination of ipilimumab plus nivolumab in different tumor types. Published studies were searched in MEDLINE, EMBASE, BIOSIS and DRUGU and abstracts were looked-up in ASCO and ESMO archives, independently. The following search terms were used: combination immunotherapy, checkpoint inhibitors combination, ipilimumab AND nivolumab.

In all the studies included in the analysis (Table 1), the Objective Response Rate (ORR) was reported; some of these also reported risk reduction (HR) in Progression Free Survival (PFS) and Overall Survival (OS).

In studies with multiple treatment arms, we only considered those including patients treated with either nivolumab alone or in combination with ipilimumab.

\section{Data extraction}

Abstract evaluation and data extraction were performed by two reviewers, independently (S.M. and D.G.). In the cases of disagreement, a third reviewer provided support. When the data for the same trial was reported in different papers, the manuscript with the longer patient follow-up was included in this meta-analysis.

Response rate was never the primary endpoint of these studies and ORR was calculated deriving data from the published paper.

\section{Statistical analysis}

Odds ratios (ORs) and their 95\% CIs were calculated for ORR as dichotomous outcomes. Hazard ratios (HRs) were summarized, and their corresponding standard errors were derived to analyze PFS and OS. The inverse variance algorithm and the Mantel-Haenszel algorithm were used. The presence/absence of heterogeneity was evaluated by calculating the $Q$ statistic, a correspondent $P<0.05$ indicated presence of heterogeneity between

Table 1 List of clinical trials included in the analysis

\begin{tabular}{|c|c|c|c|c|c|}
\hline Study & Phase & Histology & Masking & No. patients & Treatment arms \\
\hline CA209-067 [8] & 3 & Melanoma & Double-blind & 945 & $\begin{array}{l}\text { Nivolumab + Ipilimumab vs Nivolumab vs } \\
\text { Ipilimumab* }\end{array}$ \\
\hline CA209-227 [10] & 3 & Nonsmall cell lung cancer (NSCLC) & Open-label & 1189 & $\begin{array}{l}\text { Nivolumab + Ipilimumab vs chemotherapy vs } \\
\text { Nivolumab* }\end{array}$ \\
\hline IFCT-1501 MAPS2 [11] & 2 & Mesothelioma & Open-label & 108 & Nivolumab + Ipilimumab vs nivolumab \\
\hline Alliance A091401 [12] & 2 & Sarcoma & Open-label & 85 & Nivolumab + Ipilimumab vs nivolumab* \\
\hline CA209-032 [13] & $1 / 2$ & Small cell lung cancer (SCLC) & Open-label & 196 & Nivolumab + Ipilimumab and Nivolumab** \\
\hline CA209-032 [14] & $1 / 2$ & Gastric & Open-label & 108 & Nivolumab + Ipilimumab and Nivolumab** \\
\hline CA209-032 [15] & $1 / 2$ & Bladder & Open-label & 196 & Nivolumab + Ipilimumab vs nivolumab \\
\hline
\end{tabular}

*Nivo $3 \mathrm{mg}+$ IPI $1 \mathrm{mg}$. **Nivo $1 \mathrm{mg}+\mathrm{IPI} 3 \mathrm{mg}$ 
Table 2 List of clinical trials included in the ORR analysis

\begin{tabular}{lll}
\hline Study & No. patients & ORR \\
\hline CA209-067 & $n+i=314$ & $n+i=58.3 \%$ \\
& $n=316$ & $n=44.6 \%$ \\
CA209-227 & $n+i=396$ & $n+i=35.9 \%$ \\
IFCT-1501 MAPS2 & $n=396$ & $n=27.5 \%$ \\
Alliance A091401 & $n+i=54$ & $n+i=27.8 \%$ \\
& $n=54$ & $n=18.5 \%$ \\
CA209-032 (GastricCancer) & $n+i=38$ & $n+i=15.8 \%$ \\
& $n=38$ & $n=5.3 \%$ \\
CA209-032 (BladderCancer) & $n+i=49^{*}$ & $n+i=24.5 \%$ \\
& $n=59$ & $n+i=7.7 \%$ \\
CA209-032 (SCLC) & $n+i=196$ & $n=11.9 \%$ \\
& $n=78$ & $n+i=34 \%$ \\
& $n+i=147$ & $n+i=21 \%$ \\
\hline
\end{tabular}

*Nivo $3 \mathrm{mg}+$ IPI 1 mg. * Nivo 1 mg + IPI 3 mg

studies. A fixed-effect model and a random-effect model were used according to the significance of the $\mathrm{Q}$ test.
Comprehensive Meta-Analysis software was used for the analysis.

\section{Results}

A total of 7 trials were included in the analysis; treatment phase, tumor types and treatment arms are reported in Table 1. Overall, this meta-analysis includes 1313 patients treated with the nivolumab plus ipilimumab combination and 1110 patients treated with nivolumab alone. All trials reported ORR (Table 2), the Q statistic $(\mathrm{P}=0.94)$ suggested absence of heterogeneity among studies and the pooled Odds Ratio, based on the fixedeffect model, (Fig. 1) was highly favoring the combination of nivolumab plus ipilimumab with respect to nivolumab alone $(\mathrm{OR}=1.683 ; 95 \% \mathrm{CI}: 1.407-2.012 ; \mathrm{P}<0.0001)$. The superiority of combination compared to monotherapy is independent from the schedule of treatment, in particular in 4 studies the schedule was NIVO1/IPI 3 (Fig. 2) while in 5 studies was NIVO3/IPI 1 (Fig. 3). Three studies were considered for PFS analysis (Table 3), also here

\begin{tabular}{|c|c|c|c|c|c|c|}
\hline \multirow[t]{2}{*}{ Study name } & \multirow[t]{2}{*}{ Outcome } & \multicolumn{4}{|c|}{ Statistics for each study } & \multirow[b]{2}{*}{ p-Value } \\
\hline & & $\begin{array}{r}\text { Odds } \\
\text { ratio }\end{array}$ & $\begin{array}{c}\text { Lower } \\
\text { limit }\end{array}$ & $\begin{array}{c}\text { Upper } \\
\text { limit }\end{array}$ & Z-Value & \\
\hline CHECKMATE 067 & ORR & 1,734 & 1,265 & 2,377 & 3,419 & 0,001 \\
\hline CHECKMIATE 227 PDL1 & ORR & 1,472 & 1,089 & 1,990 & 2,515 & 0,012 \\
\hline IFCT-1501 & ORR & 1,692 & 0,682 & 4,199 & 1,135 & 0,257 \\
\hline A091401 & ORR & 3,375 & 0,636 & 17,922 & 1,428 & 0,153 \\
\hline CA209032_SCLC & ORR & 2,141 & 1,064 & 4,311 & 2,132 & 0,033 \\
\hline CA209302_GASTRIC * & ORR & 0,619 & 0,170 & 2,248 & $-0,729$ & 0,466 \\
\hline CA209032_BLADDER * & ORR & 1,068 & 0,548 & 2,083 & 0,194 & 0,846 \\
\hline CA209032_GASTRIC ** & ORR & 2,409 & 0,866 & 6,702 & 1,685 & 0,092 \\
\hline \multirow[t]{2}{*}{ CA209032_BLADDER ** } & ORR & 1,781 & 0,920 & 3,445 & 1,714 & 0,087 \\
\hline & & 1,599 & 1,335 & 1,915 & 5,103 & 0,000 \\
\hline
\end{tabular}

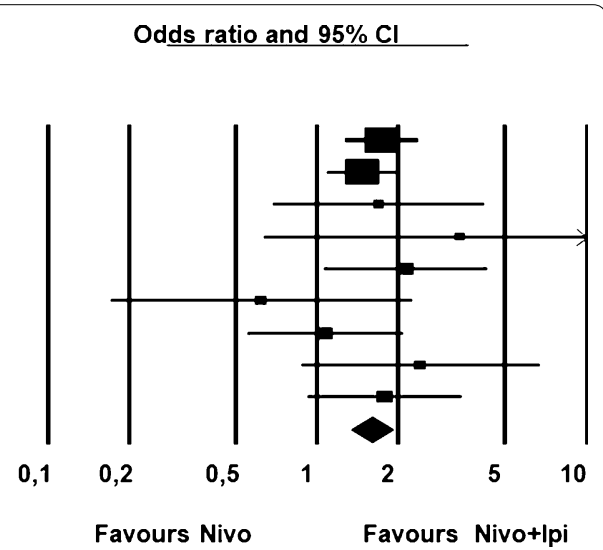

Fig. 1 Global ORR Analysis. Figure shows ORR analysis in selected trials. ORR was highly favoring the combination of nivolumab plus ipilimumab with respect to nivolumab alone $(\mathrm{OR}=1.683 ; 95 \% \mathrm{Cl}: 1.407-2.012 ; P<0.0001)$. Fixed effect model— Heterogeneity not significant $(P=0.62)$. ${ }^{*}$ Nivo $3 \mathrm{mg}+\mathrm{IPI} 1 \mathrm{mg}$. **Nivo $1 \mathrm{mg}+\mathrm{IPI} 3 \mathrm{mg}$

\begin{tabular}{|c|c|c|c|c|c|c|}
\hline \multirow[t]{2}{*}{ Study name } & \multirow[t]{2}{*}{ Outcome } & \multicolumn{4}{|c|}{ Statistics for each study } & \multirow[b]{2}{*}{ p-Value } \\
\hline & & $\begin{array}{r}\text { Odds } \\
\text { ratio }\end{array}$ & $\begin{array}{r}\text { Lower } \\
\text { limit }\end{array}$ & $\begin{array}{r}\text { Upper } \\
\text { limit }\end{array}$ & Z-Value & \\
\hline CHECKI.IATE 067 & ORR & 1.734 & 1.265 & 2.377 & 3.419 & 0.001 \\
\hline CA209032_SCLC & ORR & 2141 & 1.064 & 4311 & 2132 & 0.033 \\
\hline CA209032_GASTRIC $\times$ & ORR & 2.409 & 0.866 & 6.702 & 1.685 & 0.092 \\
\hline \multirow[t]{2}{*}{ CA209032_BLADDER ** } & ORR & 1781 & 0.920 & 3445 & 1714 & 0.087 \\
\hline & & 1.827 & 1.416 & 2.359 & 4.629 & 0.000 \\
\hline
\end{tabular}

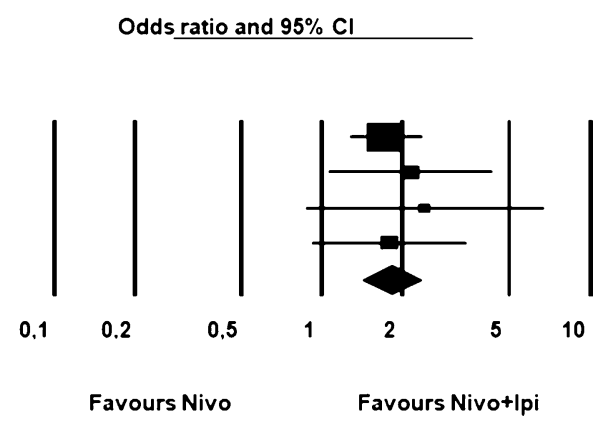

Fig. 2 ORR analysis for NIVO1/IPI3. Figure shows the ORR analysis in selected trials in which NIVO1/IPI3 schedule was administered. Fixed effect model_-Heterogeneity not significant ( $P=0.89)$. NIVO1/IPI3: nivolumab $1 \mathrm{mg} / \mathrm{kg}$ and ipilimumab $3 \mathrm{mg} / \mathrm{kg}$ 


\begin{tabular}{|c|c|c|c|c|c|c|}
\hline \multirow[t]{2}{*}{ Study name } & \multicolumn{2}{|c|}{ Outcome } & \multicolumn{3}{|c|}{ Statistics for each study } & \multirow[b]{2}{*}{ p-Value } \\
\hline & & $\begin{array}{r}\text { Odds } \\
\text { ratio }\end{array}$ & $\begin{array}{c}\text { Lower } \\
\text { limit }\end{array}$ & $\begin{array}{c}\text { Upper } \\
\text { limit }\end{array}$ & Z-Value & \\
\hline CHECKMATE 227 PDL 1 & ORR & 1,472 & 1.089 & 1,990 & 2.515 & 0.012 \\
\hline IFCT-1501 & ORR & 1,692 & 0.682 & 4,199 & 1,135 & 0,257 \\
\hline A091401 & ORR & 3,375 & 0.636 & 17,922 & 1,428 & 0.153 \\
\hline CA209302_GASTRIC * & ORR & 0,619 & 0,170 & 2,248 & $-0,729$ & 0,466 \\
\hline CA209032_BLADDER * & ORR & 1,068 & 0,548 & 2,083 & 0,194 & 0,846 \\
\hline & & 1.400 & 1.085 & 1,806 & 2.591 & 0.010 \\
\hline
\end{tabular}

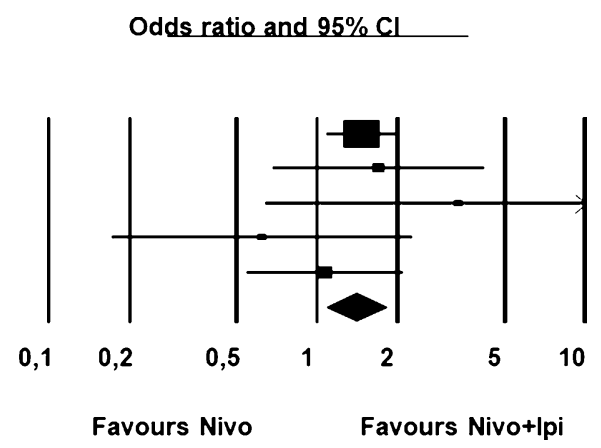

Fig. 3 ORR analysis for NIVO3/IPI1. Figure shows ORR analysis for selected trial in which was administered NIVO3/IPI1 schedule. Fixed effect model_-Heterogeneity not significant $(P=0.48)$. NIVO3/IPI1: nivolumab $3 \mathrm{mg} / \mathrm{kg}$ and ipilimumab $1 \mathrm{mg} / \mathrm{kg}$

Table 3 List of clinical trials included for PFS analysis

\begin{tabular}{|c|c|c|c|}
\hline Study & No. patients & $\begin{array}{l}\text { Median PFS } \\
\text { (months) }\end{array}$ & $H R$ \\
\hline CA209-067 & $\begin{array}{l}n+i=314 \\
n=316\end{array}$ & $\begin{array}{l}n+i=11.5 \\
n=6.93\end{array}$ & HR 0.79 \\
\hline $\begin{array}{l}\text { CA209-227 (PFS TMB } \\
\text { High) }\end{array}$ & $\begin{array}{l}n+i=101 \\
n=102\end{array}$ & $\begin{array}{l}1 y r \\
n+i=42 \% \\
n=29 \%\end{array}$ & HR 0.75 \\
\hline $\begin{array}{l}\text { CA209-227 (PFS } \\
\text { PD-L1> } 1 \% \text { ) }\end{array}$ & $\begin{array}{l}n+i=396 \\
n=396\end{array}$ & $\begin{array}{l}n+i=5.1 \\
n=4.2\end{array}$ & HR 0.83 \\
\hline
\end{tabular}

too, the Q statistic showed a P value equal to 0.85 and the pooled Hazard Ratio (Fig. 4) favored the combination of nivolumab plus ipilimumab with respect to nivolumab alone $(\mathrm{HR}=0.807 ; 95 \% \mathrm{CI}: 0.719-0.907 ; P<0.0001)$. The OS endpoint was considered only for 2 trials (Table 4) for which results were in the same direction and the pooled HR (Fig. 5) also favored the combination of nivolumab plus ipilimumab with respect to nivolumab alone $(\mathrm{HR}=0.87 ; 95 \%$ CI: $0.763-0.997 ; P=0.045)$.

The combination resulted in higher incidence of G3-G4 toxicities as shown in Fig. 6, Additional file 1: Figures S1 and S2.

\section{Discussion}

The number of cancer patients who benefit from immunotherapy has increased due to a better understanding of the immune response to cancer along with recent advances in biomarker development. In particular, an interesting component of immunotherapy is the longlasting tumor responses observed, with some patients achieving disease control for many years. Nevertheless, not all patients benefit from immunotherapy, and efforts should focus on improving the efficacy of immunotherapy through the use of both combination or sequential approaches and predictive biomarkers of response and resistance [16]. The goal of combination approaches, targeting several steps of the cancer-immunity cycle, is to

\section{Table 4 List of clinical trials included for OS analysis}

\begin{tabular}{llll}
\hline Study & No. patients & $\begin{array}{l}\text { Median OS } \\
\text { (months) }\end{array}$ & HR \\
\hline CA209-067 [1, 2] & $n+i=314$ & $n+i=N R$ & HR 0.83 \\
& $n=316$ & $n=36.93$ & \\
CA209-227 [4] & $n+i=396$ & $n+i=17.1$ & HR 0.79 \\
(OS PD-L1 1\%) & $n=396$ & $n=15.7$ & \\
\hline
\end{tabular}

\section{Study name \\ Outcome Statistics for each study Hazard Lower Upper ratio limit limit Z-Valuep-Value \\ $\begin{array}{llllllllllll}\text { CHECKMATE } 067 & \text { PFS } & 0,790 & 0,645 & 0,968 & -2,279 & 0,023\end{array}$ \\ $\begin{array}{lllllll}\text { CHECKMATE 227_TMB PFS } \quad 0,750 & 0,528 & 1,066 & -1,605 & 0,108\end{array}$ \\ CHECKMATE 227 PDL1PFS \\ $\begin{array}{lllll}0,830 & 0,710 & 0,970 & -2,341 & 0,019\end{array}$ \\ $\begin{array}{lllll}0,807 & 0,719 & 0,907 & -3,594 & 0,000\end{array}$
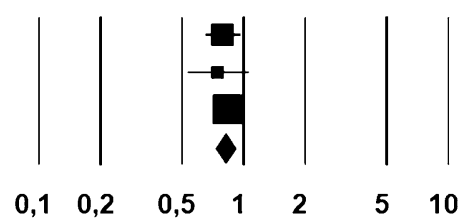 \\ Favours Nivo+Ipi Favours Nivo}

Fig. 4 PFS Analysis. Figure shows the PFS analysis on selected trials. Pooled Hazard Ratio favored the combination of nivolumab plus ipilimumab with respect to nivolumab alone ( $\mathrm{HR}=0.807 ; 95 \% \mathrm{Cl}: 0.719-0.907 ; P<0.0001)$. Fixed effect model-Heterogeneity not significant $(P=0.85)$ 


\section{Study name \\ Outcome Statistics for each study \\ Hazard ratio and $95 \% \mathrm{Cl}$ \\ Hazard LowerUpper \\ ratio limit limit Z-Valuep-Value \\ CHECKMATE 067 OS \\ $\begin{array}{llllll}0,830 & 0,669 & 1,029 & -1,698 & 0,089\end{array}$ \\ CHECKMATE 227_PDL1 OS \\ $\begin{array}{llllll}0,900 & 0,759 & 1,068 & -1,207 & 0,227\end{array}$ \\ $\begin{array}{llllll}0,872 & 0,763 & 0,997 & -2,002 & 0,045\end{array}$

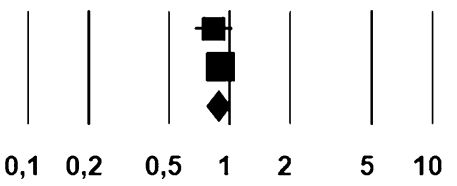 \\ Favours Nivo+lpi Favours Nivo}

Fig. 5 OS Analysis. Figure shows the OS analysis on selected trials. The pooled HR favored the combination of nivolumab plus ipilimumab with respect to nivolumab alone $(\mathrm{HR}=0.87 ; 95 \% \mathrm{Cl}: 0.763-0.997 ; P=0.045)$. Fixed effect model—Heterogeneity not significant $(P=0.56)$

\begin{tabular}{|c|c|c|c|c|c|c|}
\hline \multirow[t]{2}{*}{ Study name } & \multirow[t]{2}{*}{ Outcome } & \multicolumn{5}{|c|}{ Statistics for each study } \\
\hline & & $\begin{array}{l}\text { Odds } \\
\text { ratio }\end{array}$ & $\begin{array}{c}\text { Lower } \\
\text { limit }\end{array}$ & $\begin{array}{c}\text { Upper } \\
\text { limit }\end{array}$ & Z-Value & \\
\hline CHECKMATE 067 & G3_G4 & 5,017 & 3,541 & 7,109 & 9,071 & 0,000 \\
\hline IFCT-1501 & G3_G4 & 2,133 & 0,861 & 5,286 & 1,637 & 0,102 \\
\hline A091401 & G3_G4 & 2,167 & 0,504 & 9,311 & 1,039 & 0,299 \\
\hline CA209032_SCLC & G3_G4 & 4,042 & 2,143 & 7,626 & 4,313 & 0,000 \\
\hline CA209302_GASTRIC * & G3_G4 & 1,805 & 0,723 & 4,509 & 1,265 & 0,206 \\
\hline CA209032_BLADDER * & G3_G4 & 1,206 & 0,629 & 2,313 & 0,565 & 0,572 \\
\hline CA209032_GASTRIC ** & G3_G4 & 4,335 & 1,795 & 10,468 & 3,260 & 0,001 \\
\hline CA209032_BLADDER *夫 & G3_G4 & 1,745 & 0,909 & 3,350 & 1,672 & 0,094 \\
\hline & & 2,603 & 1,666 & 4,067 & 4,202 & 0,00 \\
\hline
\end{tabular}

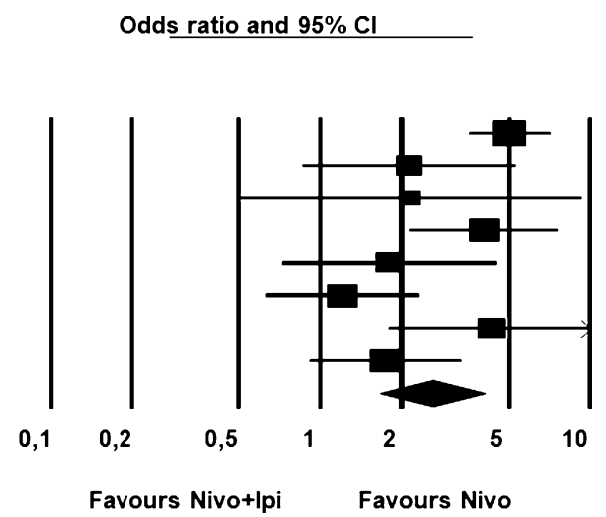

Fig. 6 Global G3/G4 toxicity analysis. Figure shows the G3/G4 toxicity analysis for all the selected trials. Nivolumab monotherapy was favored compared to the combination. Random effect model—Significant heterogeneity $(P=0.003)$. *Nivolumab $3 \mathrm{mg}+$ ipilimumab 1 mg **Nivolumab $1 \mathrm{mg}+$ ipilimumab $3 \mathrm{mg}$

expand the spectrum of patients who could respond to cancer immunotherapy (increased number of responding patients in tumors that are sensitive to single agent therapy and the identification of new sensitive tumor types that do not respond to monotherapy alone) and to improve the quality of clinical responses (i.e., time span of response, PFS and OS) beyond what can be achieved with monotherapy alone [17]. The aim of such antitumor strategies will be to raise the tail on the survival curve by increasing the number of long term survivors, while managing any additive or synergistic toxicities that may arise with immunotherapy combination. In our analysis, we found that combination therapy was superior to monotherapy. This may have several explanations: (1) the efficacy of monotherapy is limited by low response rates, with only a small proportion of patients responding to treatment; (2) combining anti-CTLA-4 and anti-PD-1 therapies may activate the antitumor immune response synergistically, thus increasing response rates; (3) combining anti-CTLA-4 and anti-PD-1 therapies significantly increases the ratios of both CD8 +/regulatory $\mathrm{T}$ cells and $\mathrm{CD} 4+$ effector/regulatory $\mathrm{T}$ cells within the tumor, so that $\mathrm{CD} 8+$ and $\mathrm{CD} 4+\mathrm{T}$ cells continue to survive, proliferate and carry out effector functions in the tumor; (4) combining anti-CTLA-4 and anti-PD-1 therapies induces the accumulation of active $\mathrm{T}$ cells that express CTLA-4 and PD-1 and would otherwise be energized; and (5) combining anti-CTLA-4 and anti-PD-1 therapies increases the production of inflammatory cytokines (such as IFN- $\gamma$ and TNF- $\alpha$ ) in the tumor itself and in its draining lymph nodes.

The scientific rationale of the combination is linked to the evidence that each immunotherapy checkpoint blockade leads to a distinct and non-overlapping signature of changes in $\mathrm{T}$ cells and the immune compartment. In particular, several investigators have demonstrated that PD-1 blockade mainly leads to changes in genes implicated in cytolysis and NK cell function, differently from CTLA-4 blockade that induces a proliferative signature in a subset of memory $\mathrm{T}$ cells. This activity of ipilimumab on the memory cell compartment may be responsible for the prolonged responses observed in patients treated with this drug. Indeed, although objective antitumor response rates 
were low $(\sim 10 \%)$, approximately $20 \%$ of patients had a long-lasting response up to 10 years and this sustained benefit may represent the potential of anti-CTLA4 immunotherapy in raising the tail of the survival curve. This effect on immunologic memory can be further demonstrated by the observation that less than 4 doses of ipilimumab can be sufficient to induce the long-term effect on the survival curve.

In intermediate/poor risk metastatic renal cell carcinoma, first-line therapy withthe combination ipilimumab plus nivolumab showed that $60 \%$ of patients were alive at 30 months, with a $42 \%$ ORR and $11 \%$ CR. In untreated advanced melanoma nivolumab plus ipilimumab versus nivolumabalone results in higher 5 -yr OS [ $52 \%$ versus $46 \%$ ) with HR of 0.83 (95\% CI, 0.67-1.03)], and PFS [37\% versus, $31 \%$ with $\mathrm{HR} 0.79$ (95\% CI, 0.64-0.96)]. These differences were consistent across many clinically relevant subgroups, including BRAF-mutant patients and poor prognostic subgroups, such as patients with elevated LDH levels and M1c disease. First-line therapy for nonsmall-cell lung cancer using combination nivolumab plus ipilimumab in patients with a PD-L1 expression level of $1 \%$ or more, shows a median overall survival of 17.1 months and 15.7 months with nivolumab alone [HR $0.90(0.76-1.07)]$ and a 2 year overall survival rate of 40.0 and $36 \%$, respectively. The median duration of response was 23.2 months with nivolumab plus ipilimumab and 15.5 months with nivolumab. Overall survival benefit was also observed in patients with a PD-L1 expression level of less than $1 \%$, with a median duration of 17.2 months (95\% CI, 12.8-22.0) with nivolumab plus ipilimumab. Preliminary but very encouraging results derive from the combination of ipilimumab plus nivolumab in melanoma patients treated in the neoadjuvant setting, achieving $78 \%$ of pathological response [18].

In this analysis, we confirmed, in a larger population with several cancer subtypes, the results of Yang and colleagues [19]. In particular we demonstrate that the addition of ipilimumab to nivolumab increases ORR to approximately 68\% (range 8-95) and reduces the risk of progression and death of about 20\% (range 10-28) and $13 \%$ (range 1-24), respectively, regardless of tumor type.

Additional evidences of the improved outcome by adding ipilimumab to nivolumab ("boost" cycles) in metastatic RCC patients, with early significant progressive disease (PD) at week 8 or stable disease (SD) or PD at week 16 during nivolumab induction, has been reported in the Titan trial [20]. Of the 207 patients enrolled in the study, 64.3\% (133/207) received at least one "boost" cycle. Overall 29.8\% (14/47) of RCC patients in first line treatment and $38.6 \%(22 / 57)$ of patients in second line treatment with SD/PD after nivolumab monotherapy had improvement in best overall response (BOR) with the "boost" cycles, respectively.

From a safety point of view, no new signals have been observed with the combination compared to monotherapy and, despite the higher level of immune relate adverse events (irAE) observed with the combination therapy, it is worth noting that: (1) patients who were required to come off treatment due to irAE had an overall benefit when compared to the entire population and (2) toxicity of the combination appears to be as manageable as single agent immunotherapy and it has been demonstrated that the need to treat irAE with corticosteroids does not impact on outcome.

However, the added benefit of each additional drug must be properly evaluated against the added toxicities, even if no new signals have been observed with the combination compared to the monotherapy.

\section{Conclusion}

The "agnostic evaluation" of the ipilimumab plus nivolumab combination suggests the "agnostic efficacy" of the combination, compared to mono-immunotherapy, in the population selected for immunotherapy treatment, regardless of tumor type.

\section{Supplementary information}

Supplementary information accompanies this paper at https://doi. org/10.1186/s12967-020-02588-2.

Additional file 1: Figure S1. G3/G4 toxicity analysis for NIVO1+IPI3 schedule. Figure S2. G3/G4 toxicity analysis for NIVO3+IPI1 schedule.

Acknowledgements

Not applicable

Authors' contributions

PM: Conception, design or planning of the study, acquisition and analysis of the data, interpretation of the results and drafting of the manuscript. DG: Analysis of the data, interpretation of the results and drafting of the manuscript. $A B$ : Analysis of the data and interpretation of the results. PM, DG, AB: Interpretation of the results. GC, PA: Analysis of the data and interpretation of the results. PM, GC, PA,AB: Interpretation of the results. PM, DG: Conception, design or planning of the study, analysis of the data and interpretation of the results. All authors read and approved the final manuscript.

Funding

Not applicable.

Availability of data and materials

The datasets used and/or analyzed during the current study are available from the corresponding author on reasonable request.

Ethics approval and consent to participate Not applicable.

Consent for publication

Not applicable. 


\section{Competing interests}

Not applicable.

\section{Author details}

${ }^{1}$ Department of Clinical and Molecular Medicine, Sapienza, University of Rome, Policlinico Umberto I, Sant'Andrea Hospital, IDI IRCSS, Rome, Italy. ${ }^{2}$ Instituto Nazionale Tumori Istituto di Ricovero e Cura a Carattere Scientifico Fondazione Pascale, Naples, Italy. ${ }^{3}$ Department of Oncology and Hemato-Oncology, University of Milano and European Institute of Oncology, IRCCS, Milano, Italy. ${ }^{4}$ Biostatistics Unit, National Cancer Institute Regina Elena IRCCS, Rome, Italy.

Received: 17 August 2020 Accepted: 26 October 2020

Published online: 25 November 2020

\section{References}

1. Looney AM, Nawaz K, Webster RM. Tumour-agnostic therapies. Nat Rev Drug Discov. 2020;19(6):383-4. https://doi.org/10.1038/d41573-02000015-1.

2. Smyth MJ, et al. Combination cancer immunotherapies tailored to the tumor microenvironment. Nat Rev Clin Oncol. 2015;13(3):143-58. https:// doi.org/10.1038/nrclinonc.2015.209.

3. Robert C, Thomas L, Bondarenko I, et al. Ipilimumab plus dacarbazine for previously untreated metastatic melanoma. N Engl J Med. 2011;364(26):2517-26.

4. O'Donnell JS, et al. Resistance to PD1/PDL1 checkpoint inhibition. Cancer Treat Rev. 2017;52:71-81.

5. Motzer RJ, et al. Nivolumab plus ipilimumab versus sunitinib in first-line treatment for advanced renal cell carcinoma: extended follow-up of efficacy and safety results from a randomised, controlled, phase 3 trial. Lancet Oncol. 2019. https://doi.org/10.1016/S1470-2045(19)30413-9.

6. Das R, et al. Combination therapy with Anti-CTLA-4 and Anti-PD-1 leads to distinct immunologic changes in vivo. J Immunol. 2015;194:950-9.

7. Wang WD, et al. Biomarkers on melanoma patient $T$ cells associated with ipilimumab treatment. J Transl Med. 2012;10:146.

8. Hodi FS, Chiarion-Sileni V, Gonzalez R, Grob JJ, Rutkowski P, Cowey CL, Lao CD, Schadendorf D, Wagstaff J, Dummer R, Ferrucci PF, Smylie M, Hill A, Hogg D, Marquez-Rodas I, Jiang J, Rizzo J, Larkin J, Wolchok JD. Nivolumab plus ipilimumab or nivolumab alone versus ipilimumab alone in advanced melanoma (CheckMate 067): 4-year outcomes of a multicenter randomised, phase 3 trial. Lancet Oncol. 2018;19(11):1480-92. https://doi.org/10.1016/S1470-2045(18)30700-9 (Epub 2018 Oct 22).

9. Larkin J, Chiarion-Sileni V, Gonzalez R, Grob JJ, Rutkowski P, Lao CD, Cowey CL, Schadendorf D, Wagstaff J, Dummer R, Ferrucci PF, Smylie M, Hogg D, Hill A, Márquez-Rodas I, Haanen J, Guidoboni M, Maio M, Schöffski P, Carlino MS, Lebbé C, McArthur G, Ascierto PA, Daniels GA, Long GV, Bastholt L, Rizzo Jl, Balogh A, Moshyk A, Hodi FS, Wolchok JD. Five-Year Survival with Combined Nivolumab and Ipilimumab in Advanced Melanoma. N Engl J Med. 2019;381(16):1535-46. https://doi.org/10.1056/NEJMoa1910 836 (Epub 2019 Sep 28)

10. Hellmann MD, Paz-Ares L, Bernabe Caro R, Zurawski B, Kim SW, Carcereny Costa E, Park K, Alexandru A, Lupinacci L, de la Mora JE, Sakai H, Albert I, Vergnenegre A, Peters S, Syrigos K, Barlesi F, Reck M, Borghaei H, Brahmer JR, O'Byrne KJ, Geese WJ, Bhagavatheeswaran P, Rabindran SK, Kasinathan RS, Nathan FE, Ramalingam SS. Nivolumab plus ipilimumab in advanced non-small-cell lung cancer. N Engl J Med. 2019;381(21):2020-31. https://doi.org/10.1056/NEJMoa1910231 (Epub 2019 Sep 28 PMID: 31562796 )

11. Scherpereel A, Mazieres J, Greillier L, Lantuejoul S, Dô P, Bylicki O, Monnet I, Corre R, Audigier-Valette C, Locatelli-Sanchez M, Molinier O, Guisier F, Urban T, Ligeza-Poisson C, Planchard D, Amour E, Morin F, Moro-Sibilot D, Zalcman G, French Cooperative Thoracic Intergroup. Nivolumab or nivolumab plus ipilimumab in patients with relapsed malig- nant pleural mesothelioma (IFCT-1501 MAPS2):

a multicentre, open-label, randomised, non-comparative, phase 2 trial. Lancet Oncol. 2019;20(2):239-53. https://doi.org/10.1016/S1470 -2045(18)30765-4 (Epub 2019 Jan 16).

12. D'Angelo SP, Mahoney MR, Van Tine BA, Atkins J, Milhem MM, Jahagirdar BN, Antonescu CR, Horvath E, Tap WD, Schwartz GK, Streicher H. Nivolumab with or without ipilimumab treatment for metastatic sarcoma (Alliance A091401): two open-label, non-comparative, randomised, phase 2 trials. Lancet Oncol. 2018;19(3):416-26. https://doi.org/10.1016/S1470 -2045(18)30006-8 (Epub 2018 Jan 19).

13. Antonia SJ, et al. Nivolumab alone and nivolumab plus ipilimumab in recurrent small-cell lung cancer (CheckMate 032): a multicentre, open-label, phase 1/2 trial. Lancet Oncol. 2016;17(7):883-95. https://doi. org/10.1016/S1470-2045(16)30098-5 (Epub 2016 Jun 4).

14. Janjigian $Y$, et al. Nivolumab \pm ipilimumab in pts with advanced (adv)/ metastatic chemotherapy-refractory (CTx-R) gastric (G), esophageal (E), or gastroesophageal junction (GEJ) cancer: Check Mate 032 study. J Clin Oncol. 2017;35(15 suppl):4014-4014.

15. Sharma $\mathrm{P}$, et al. Nivolumab monotherapy in recurrent metastatic urothelial carcinoma (CheckMate 032): a multicentre, open-label, two-stage, multi-arm, phase 1/2 trial. Lancet Oncol. 2016;17:1590-8. https://doi. org/10.1016/S1470-2045(16)30496-X (Epub 2016 Oct 9).

16. Bedognetti D, Ceccarelli M, Galluzzi L, Lu R, Palucka K, Samayoa J, Spranger S, Warren S, Wong KK, Ziv E, Chowell D, Coussens LM, De Carvalho DD, DeNardo DG, Galon J, Kaufman HL, Kirchhoff T, Lotze MT, Luke JJ, Minn AJ, Politi K, Shultz LD, Simon R, Thórsson V, Weidhaas JB, Ascierto ML, Ascierto PA, Barnes JM, Barsan V, Bommareddy PK, Bot A, Church SE, Ciliberto G, De Maria A, Draganov D, Ho WS, McGee HM, Monette A, Murphy JF, Nisticò P, Park W, Patel M, Quigley M, Radvanyi L, Raftopoulos $H$, Rudqvist NP, Snyder A, Sweis RF, Valpione S, Zappasodi R, Butterfield LH, Disis ML, Fox BA, Cesano A, Marincola FM, Society for Immunotherapy of Cancer (SITC) Cancer Immune Responsiveness Task Force and Working Groups. Toward a comprehensive view of cancer immune responsiveness: a synopsis from the SITC workshop. J Immunother Cancer. 2019;7(1):131. https://doi.org/10.1186/s40425-019-0602-4.

17. Sharma P, Allison JP. The future of immune checkpoint therapy. Science. 2015;348(6230):56-61. https://doi.org/10.1126/science.aaa8172.

18. Rozeman EA, Menzies AM, van Akkooi ACJ, Adhikari C, Bierman C, van de Wiel BA, Scolyer RA, Krijgsman O, Sikorska K, Eriksson H, Broeks A, van Thienen JV, Guminski AD, Acosta AT, TerMeulen S, Koenen AM, Bosch LJW, Shannon K, Pronk LM, Gonzalez M, Ch'ng S, Grijpink-Ongering LG, Stretch J, Heijmink S, van Tinteren H, Haanen JBAG, Nieweg OE, Klop WMC, Zuur CL, Saw RPM, van Houdt WJ, Peeper DS, Spillane AJ, Hansson J, Schumacher TN, Long GV, Blank CU. Identification of the optimal combination dosing schedule of neoadjuvant ipilimumab plus nivolumab in macroscopic stage III melanoma (OpACIN-neo): a multicentre, phase 2, randomised, controlled trial. LancetOncol. 2019;20(7):948-60. https://doi. org/10.1016/S1470-2045(19)30151-2 (Epub 2019 May 31).

19. Yang Yi, Jin G, Pang Y, Huang Y, Wang W, Zhang H, Tuo G, Peng Wu, Wang Z, Zhu Z. Comparative efficacy and safety of nivolumab and nivolumab plus ipilimumab in advanced cancer: a systemic review and metaanalysis. Front Pharmacol. 2020;11:40. https://doi.org/10.3389/fphar 2020.00040

20. Grimm MO, Schmidinger M, Martinez ID, Schinzari G, Esteban E, Schmitz M, Schumacher U, Baretton G, Barthelemy P, Melichar B, Charnley N. TAILORED IMMUNOTHERAPY APPROACH WITH NIVOLUMAB IN ADVANCED RENAL CELL CARCINOMA (TITAN-RCC). Ann Oncol. 2019;30(suppl 5):v851-934. https://doi.org/10.1093/annonc/mdz394.

\section{Publisher's Note}

Springer Nature remains neutral with regard to jurisdictional claims in published maps and institutional affiliations. 